\title{
Small-Animal PET of Steroid Hormone Receptors Predicts Tumor Response to Endocrine Therapy Using a Preclinical Model of Breast Cancer
}

\author{
Amy M. Fowler ${ }^{1}$, Szeman Ruby Chan ${ }^{2}$, Terry L. Sharp ${ }^{1}$, Nicole M. Fettig ${ }^{1}$, Dong Zhou ${ }^{1}$, Carmen S. Dence ${ }^{1}$, \\ Kathryn E. Carlson ${ }^{3}$, M. Jeyakumar ${ }^{3}$, John A. Katzenellenbogen ${ }^{3}$, Robert D. Schreiber ${ }^{2}$, and Michael J. Welch ${ }^{\dagger 1}$ \\ ${ }^{1}$ Division of Radiological Sciences, Edward Mallinckrodt Institute of Radiology, St. Louis, Missouri; ${ }^{2}$ Department of Pathology and \\ Immunology, Washington University School of Medicine, St. Louis, Missouri; and ${ }^{3}$ Department of Chemistry, University of Illinois at \\ Urbana-Champaign, Urbana, Illinois
}

\begin{abstract}
Estrogen receptor- $\alpha(E R \alpha)$ and progesterone receptor $(\mathrm{PR})$ are expressed in most human breast cancers and are important predictive factors for directing therapy. Because of de novo and acquired resistance to endocrine therapy, there remains a need to identify which $\mathrm{ER} \alpha$-positive $\left(\mathrm{ER} \alpha^{+}\right) / \mathrm{PR}$-positive size. This work demonstrates that imaging baseline tumoral ${ }^{18} \mathrm{~F}-\mathrm{FES}$ uptake and initial changes in ${ }^{18} \mathrm{~F}$-FFNP uptake in a noninvasive manner is a potentially useful strategy to identify responders and nonresponders to endocrine therapy at an early stage.
\end{abstract} $\left(\mathrm{PR}^{+}\right)$tumors are most likely to respond. The purpose of this study was to use estrogen- and progestin-based radiopharmaceuticals to image $\mathrm{ER} \alpha$ and PR in mouse mammary tumors at baseline and after hormonal therapy and to determine whether changes in these imaging biomarkers can serve as an early predictive indicator of therapeutic response. Methods: Mammary adenocarcinomas that spontaneously develop in aged female mice deficient in signal transducer and activator of transcription-1 (STAT1) were used. Imaging of ER $\alpha$ and PR in primary tumor-bearing mice and mice implanted with mammary cell lines (SSM1, SSM2, and SSM3) derived from primary STAT1-deficient (STAT1 ${ }^{-1}{ }^{-}$) tumors was performed. Hormonal treatments consisted of estradiol, an ER agonist; letrozole, an aromatase inhibitor; and fulvestrant, a pure ER antagonist. Small-animal PET/CT was performed using ${ }^{18} \mathrm{~F}$-fluoroestradiol $\left({ }^{18} \mathrm{~F}-\mathrm{FES}\right)$ for ER, ${ }^{18} \mathrm{~F}$-fluoro furanyl norprogesterone ( $\left.{ }^{18} \mathrm{~F}-\mathrm{FFNP}\right)$ for PR, and ${ }^{18} \mathrm{~F}-\mathrm{FDG}$ for glucose uptake. Tracer uptake in the tumor was quantified and compared with receptor concentration determined by in vitro assays of resected tumors. Results: Primary STAT1 ${ }^{-1-}$ mammary tumors and implanted SSM2 and SSM3 tumors showed high ${ }^{18} \mathrm{~F}-\mathrm{FES}$ and ${ }^{18} \mathrm{~F}-\mathrm{FFNP}$ uptake and were confirmed to be $\mathrm{ER}^{+} / \mathrm{PR}^{+}$. Classic estrogen-induced regulation of the progesterone receptor gene was demonstrated by increased ${ }^{18} \mathrm{~F}-\mathrm{FFNP}$ uptake of estradiol-treated SSM3 tumors. Treatment with fulvestrant decreased ${ }^{18} \mathrm{~F}-\mathrm{FFNP}$, ${ }^{18} \mathrm{~F}-\mathrm{FES}$, and ${ }^{18} \mathrm{~F}-\mathrm{FDG}$ uptake and inhibited growth of SSM3 tumors but decreased only ${ }^{18} \mathrm{~F}-\mathrm{FES}$ uptake in SSM2 tumors, with no effect on growth, despite both tumors being $\mathrm{ER}^{+}$/ $\mathrm{PR}^{+}$. Decreased ${ }^{18} \mathrm{~F}-\mathrm{FFNP}$ uptake by SSM3 tumors occurred early after initiation of treatment, before measurable tumor growth inhibition. Conclusion: Using small-animal PET, a profile was identified that distinguished fulvestrant-sensitive from ful-

Received Feb. 17, 2012; revision accepted May 11, 2012.

For correspondence or reprints contact: Amy M. Fowler, Mallinckrodt Institute of Radiology, Campus Box 8131, 510 S. Kingshighway Blvd., St. Louis, MO 63110.

E-mail: fowlera@mir.wustl.edu

†Deceased.

Published online Jun. 5, 2012

COPYRIGHT @ 2012 by the Society of Nuclear Medicine, Inc. vestrant-resistant $\mathrm{ER} \alpha^{+} / \mathrm{PR}^{+}$tumors before changes in tumor

Key Words: PET imaging; estrogen receptor; progesterone receptor; breast cancer; endocrine therapy

J Nucl Med 2012; 53:1119-1126

DOI: 10.2967/jnumed.112.103465

$\mathbf{E}$ strogen receptor- $\alpha(E R \alpha)$ is expressed in most human breast cancers and is an important predictive factor for directing therapy. Compared with patients with ER $\alpha$-negative tumors, patients with $\mathrm{ER} \alpha$-positive $\left(\mathrm{ER} \alpha^{+}\right)$tumors typically have longer overall survival and are more likely to respond to hormonebased therapies designed to decrease endogenous estrogens or block ER transcriptional activity, such as aromatase inhibitors, tamoxifen, or fulvestrant. However, some patients with $\mathrm{ER} \alpha^{+}$ tumors do not respond to endocrine therapy (1).

The progesterone receptor gene $(P G R)$ is a classic estrogen-stimulated target gene, and currently both ER $\alpha$ and progesterone receptor (PR) are routinely measured using immunohistochemistry as part of the pathologic assessment of breast cancer (2). Although immunohistochemistry is the current gold standard for detecting steroid hormone receptor expression, noninvasive imaging offers several advantages. For instance, imaging can assess the entire lesion, which is advantageous for tumors with heterogeneous receptor expression that could lead to biopsy sample error. Furthermore, noninvasive imaging is useful for metastatic lesions that may be technically difficult to biopsy or for patients at high risk for biopsy-related complications. Repeated imaging can assess whole-body disease burden over time, as one cannot presume that recurrent or metastatic lesions retain the same steroid hormone expression profile as the primary tumor and discordance occurs in up to $30 \%$ of the patients who ultimately have a decreased response to hormonal therapy $(3,4)$. 
The ability of these nuclear receptors to bind ligand provides a convenient target for the development of imaging agents (5). The estrogen-based radiopharmaceutical ${ }^{18} \mathrm{~F}$ fluoroestradiol ( $\left.{ }^{18} \mathrm{~F}-\mathrm{FES}\right)$ has high specific activity, binding affinity, and selectivity for ER $\alpha$ over the ER $\beta$ subtype (6) and has been shown to exhibit high specific uptake by ERrich target tissues and $\mathrm{ER} \alpha^{+}$mammary tumors using smallanimal models $(7,8)$. For human breast cancer patients, use of ${ }^{18} \mathrm{~F}$-FES PET as a measure of tumoral ER $\alpha$ expression has been validated by the gold standards of immunohistologic and biochemical receptor assays with significant concordance (9-11). ${ }^{18} \mathrm{~F}-\mathrm{FES}$ imaging has also been shown to be a predictive assay for endocrine therapy since patients with pretreatment ${ }^{18} \mathrm{~F}$-FES standardized uptake values greater than 1.5-2.0 correlate with a positive response to therapy $(12,13)$. Although not as well studied as ${ }^{18} \mathrm{~F}-\mathrm{FES}$, progestin-based radiopharmaceuticals such as ${ }^{18} \mathrm{~F}$-fluoro furanyl norprogesterone $\left({ }^{18} \mathrm{~F}\right.$-FFNP) have been developed for PR imaging as an indicator of a functionally intact $E R \alpha$ signaling pathway (14). Preclinical studies have demonstrated high ${ }^{18}$ F-FFNP uptake in the uterus and ovaries of estrogenprimed immature female rats (14), and initial results for ${ }^{18}$ F-FFNP imaging of human breast cancer patients have recently been published (15).

The goal of this study was to determine whether changes in tumoral steroid hormone receptor expression as assessed by molecular imaging after endocrine therapy are of predictive value using a preclinical animal model of human luminal breast cancer. Disruption of the gene for the signal transducer and activator of transcription-1 (STAT1) in mice results in a complete lack of responsiveness to interferons and, interestingly, spontaneous development of mammary tumors (16). These adenocarcinomas are remarkably similar to human luminal breast cancers since they express ER $\alpha$ and PR, require ovarian hormones for growth, and have significantly overlapping gene expression profiles (17). Furthermore, the tumors are HER2/neu-negative (17) and have no detectable epidermal growth factor receptor or ER $\beta$ protein expression (Szeman Ruby Chan and Robert D. Schreiber, unpublished data, May 29, 2012). In the current study, we performed ${ }^{18} \mathrm{~F}$-FES and ${ }^{18} \mathrm{~F}$-FFNP PET of primary and implanted STAT1-deficient $\left(\right.$ STAT1 $^{-\prime-}$ ) mammary tumors at baseline and in response to fulvestrant, a pure ER $\alpha$ antagonist, to determine whether changes in these imaging biomarkers can serve as an early predictive indicator of the ultimate response to therapy. An imaging approach that successfully predicts tumor response to standard endocrine therapy would be a useful tool for the further evaluation of novel breast cancer treatments.

\section{MATERIALS AND METHODS}

\section{Cell Culture, Tumor Implantation, and Hormone Treatments}

Spontaneous $\mathrm{STAT}^{-/-}$mammary (SSM) tumor cell lines (SSM1, SSM2, and SSM3) generated from 3 independent primary tumors (17) were maintained in Dulbecco modified Eagle/F12 medium supplemented with $10 \%$ fetal bovine serum, $1 \%$ L-glutamine, $1 \%$ penicillin-streptomycin, $50 \mu \mathrm{M}$ 2-mercaptoethanol, and $5 \mu \mathrm{g} / \mathrm{mL}$ and $10 \mathrm{ng} / \mathrm{mL}$ concentration of insulin and transferrin, respectively. Wild-type (WT) $129 \mathrm{~S} 6 / \mathrm{SvEv}$ and STAT1 ${ }^{-1-}$ (129S6/ SvEv) female mice were purchased from Taconic Farms, Inc., and fed an estrogen-free diet (Harlan Teklad). All animal experiments were performed according to the Guidelines for the Care and Use of Research Animals established by Washington University's Animal Studies Committee. Intact female WT mice 6-8 wk old were injected subcutaneously with $10^{6}$ SSM1, SSM2, or SSM3 mammary tumor cells in $100 \mu \mathrm{L}$ into the right thoracic mammary fat pad. Tumor growth was monitored by palpation and measured in 2 perpendicular dimensions with calipers. The average of the 2 perpendicular measurements was plotted as mean tumor diameter.

Letrozole (50 $\mu \mathrm{g}$ per mouse once daily; Sigma) was administered via intraperitoneal injection. $17 \beta$-estradiol $(20 \mu \mathrm{g}$ per mouse once daily; Sigma) and fulvestrant (5 mg [in sunflower oil] per mouse once weekly; Sigma) were administered via subcutaneous injection.

\section{Radiopharmaceuticals and Small-Animal PET}

${ }^{18}$ F-FDG was provided by the Cyclotron Facility at Washington University. ${ }^{18}$ F-FFNP was synthesized as described by Dehdashti et al. (15) using a methanesulfonate precursor (18) under typical labeling conditions (potassium carbonate, Kryptofix 222 [Merck], acetonitrile, $85^{\circ} \mathrm{C}, 5 \mathrm{~min}$ ) (19). $16 \alpha^{-18} \mathrm{~F}$-FES was synthesized according to the literature (20), with modifications (21). Specific activities were measured using standard analytic high-performance liquid chromatography and exceeded $65 \mathrm{GBq}(1,746 \mathrm{mCi}) / \mu \mathrm{mol}$ for ${ }^{18} \mathrm{~F}-\mathrm{FFNP}$ and $113 \mathrm{GBq}(3,048 \mathrm{mCi}) / \mu \mathrm{mol}$ for ${ }^{18} \mathrm{~F}-\mathrm{FES}$.

The mice were injected in the tail vein with $11.1 \mathrm{MBq}(300$ $\mu \mathrm{Ci})$ of ${ }^{18} \mathrm{~F}-\mathrm{FDG}, 11.1 \mathrm{MBq}(300 \mu \mathrm{Ci})$ of ${ }^{18} \mathrm{~F}-\mathrm{FFNP}$, or $5.55 \mathrm{MBq}$ $(150 \mu \mathrm{Ci})$ of ${ }^{18} \mathrm{~F}$-FES on separate imaging days. Before ${ }^{18} \mathrm{~F}-\mathrm{FDG}$ administration, the mice were kept fasting for at least $6 \mathrm{~h}$. Images were acquired with a small-animal PET/CT scanner (Inveon and Focus-220; Siemens Preclinical Solutions) $1 \mathrm{~h}$ after injection of the radiotracer. A 10 -min scan with a ${ }^{57}$ Co transmission source was performed for attenuation correction, followed by a 10-min static emission scan. Images were reconstructed using a maximum a posteriori algorithm (22) and were coregistered with CT images to identify the regions of interest. The PET images were quantified using Inveon Research Workplace 3.0 (Siemens Medical Solutions USA, Inc.). Regions of interest were manually drawn within the tumor on the PET/CT images and, as a measure of nontarget tissue activity, within the triceps muscle. Activity measurements (Bq/ $\mathrm{cm}^{3}$ ) were divided by the decay-corrected injected dose (Bq) and multiplied by 100 to obtain a tissue uptake index expressed as percentage injected dose per gram of tissue.

\section{In Vitro Receptor Assays}

For Western blot analysis, the excised frozen tumors were crushed with a cryogenic tissue pulverizer (Cellcrusher; Ballina). Whole-cell lysates were obtained using a 1:1 volume of radioimmunoprecipitation assay buffer (Sigma) containing $2 \mathrm{mM}$ sodium vanadate, protease inhibitor cocktail (1:500, Sigma), and phosphatase inhibitor cocktail (1:100, Sigma). Protein concentration in the supernatant was determined using the Bradford method. One hundred micrograms of lysate were resolved using $7.5 \%$ sodium dodecylsulfate-polyacrylamide gel electrophoresis and transferred onto nitrocellulose membranes. Primary antibodies included anti-ER $\alpha$ (1:100, clone 6F11, VP-E613; Vector Laboratories), anti-PR (1:1,000, sc-538; Santa Cruz Biotechnology), and anti- $\beta$-actin (1:5,000, clone AC-74; Sigma). Secondary antibodies 
included goat antimouse IgG IRDye800 conjugated (1:10,000; Rockland Immunochemicals) and Alexa Fluor 680 goat antirabbit IgG highly cross-adsorbed (1:20,000; Invitrogen). Protein bands were visualized and quantified using the Odyssey Infrared Imaging System (LI-COR Biotechnology). Full-length recombinant human $\mathrm{ER} \alpha$ protein (Invitrogen) was used to generate standard curves for semiquantitative receptor measurement in the tumor samples according to the method used by Saji et al. (23). Molar concentrations of ER $\alpha$ were calculated using linear regression ( $r^{2}$ values ranged from 0.966 to 0.997 ) and are expressed as $\mathrm{fmol} / \mathrm{mg}$ of total protein extract. Competitive ER and PR ligand binding assays with ${ }^{3} \mathrm{H}$-estradiol and ${ }^{3} \mathrm{H}$-promegestone, respectively, were used to determine receptor concentrations as described previously (24).

\section{Statistical Analyses}

Tumor growth curves were analyzed by a freely distributed test available at http://www.stat.ucl.ac.be/ISpersonnel/lecoutre/Tgca/ english/index3.html. An unpaired $t$ test was used to determine statistical significance between experimental and control groups. All tests were 2 -sided, and a $P$ value of less than 0.05 was considered significant. Analyses were performed using Prism, version 5.04 (GraphPad Software).

\section{RESULTS}

\section{${ }^{18}$ F-FES and ${ }^{18}$ F-FFNP Uptake of Primary STAT1 ${ }^{-/-}$} Mouse Mammary Tumors

We investigated the in vivo steroid hormone receptor status of primary mammary tumors in aged female STAT $1^{-1-}$ mice using small-animal PET/CT with ${ }^{18} \mathrm{~F}$ FES and ${ }^{18} \mathrm{~F}$-FFNP for $\mathrm{ER} \alpha$ and PR, respectively. The mean age of the mice was $61 \mathrm{wk}$ (range, 55-68 wk). The average ratio of tumor-to-muscle uptake (T:M) was 4.5 and 4.4 for ${ }^{18} \mathrm{~F}$-FES and ${ }^{18} \mathrm{~F}$-FFNP imaging, respectively (Figs. $1 \mathrm{~A}$ and $1 \mathrm{~B})$. For reference, uterine ${ }^{18} \mathrm{~F}$-FES uptake measured with biodistribution studies was $12.2 \pm 1.4$ percentage injected dose/g, which yielded an average T:M of 42 . Western blot analysis showed that the tumors expressed $\mathrm{ER} \alpha$ and PR protein (Supplemental Fig. 1), consistent with immunohistochemical results previously reported (17) and with their receptor profile determined by imaging (Fig. 1). In the 4 tumors examined, there was a predominance of the PR-A isoform. Also noted was a phosphorylated form of PR-A, which appeared as a doublet at the expected molecular size of PR-A because of slower electrophoretic migration of the phosphorylated protein (25). Thus, the mammary tumors that develop spontaneously in STAT1 ${ }^{-1-}$ mice are $\mathrm{ER} \alpha^{+} / \mathrm{PR}$-positive $\left(\mathrm{PR}^{+}\right)$and can be detected in vivo with ${ }^{18} \mathrm{~F}$-FES and ${ }^{18} \mathrm{~F}$-FFNP imaging.

\section{${ }^{18} \mathrm{~F}-\mathrm{FES},{ }^{18} \mathrm{~F}-\mathrm{FFNP}$, and ${ }^{18} \mathrm{~F}-\mathrm{FDG}$ Uptake of Implanted STAT1 $^{-1-}$ Tumor Cell Lines}

Because the development of primary STAT1 ${ }^{-/-}$mammary tumors requires a long latency and is thus not synchronous, 3 SSM tumor cell lines, SSM1, SSM2, and SSM3, were used in subsequent experiments. These tumor cell lines were generated from independent primary tumors and can be propagated in vitro and implanted in the mammary fat pad for expedited experimentation (17). The SSM

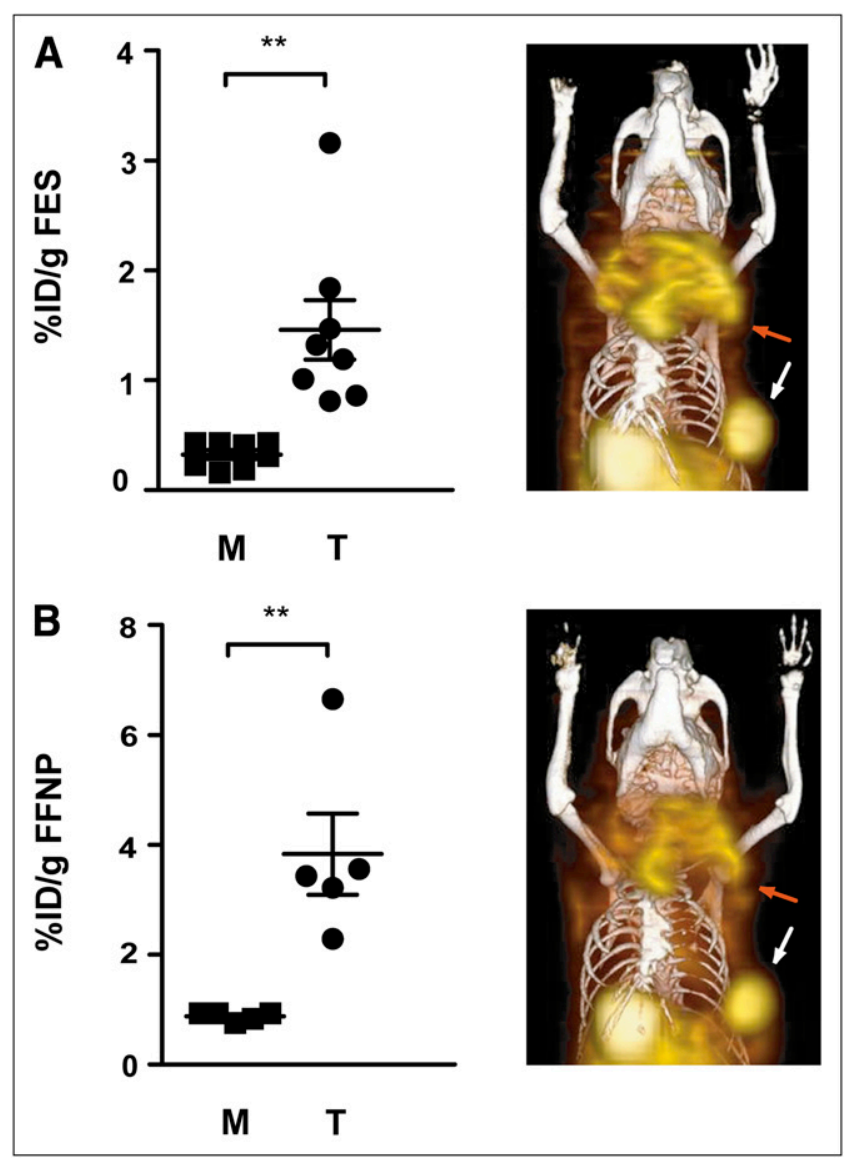

FIGURE 1. Aged female STAT1 ${ }^{-/-}$mice with primary mammary tumors were imaged with small-animal PET/CT using ${ }^{18} \mathrm{~F}-\mathrm{FES}$ (7 mice; 8 tumors) (A) and ${ }^{18} \mathrm{~F}-\mathrm{FFNP}$ (4 mice; 5 tumors) (B). Activity in tumor and muscle was measured and graphed. Coronal 3-dimensional fused small-animal PET/CT images are shown for mouse with large primary tumor in left upper thoracic fat pad (red arrow) and smaller tumor in left lower thoracic fat pad (white arrow). Intense physiologic activity is present in gallbladder and bowel, consistent with hepatobiliary clearance. ${ }^{\star \star} P<0.01$.

cell lines were implanted into WT female mice, and tumors were imaged with ${ }^{18} \mathrm{~F}$-FES, ${ }^{18} \mathrm{~F}$-FFNP, and ${ }^{18} \mathrm{~F}$-FDG PET as a marker of tumor glucose metabolism.

The highest ${ }^{18} \mathrm{~F}$-FES and ${ }^{18} \mathrm{~F}$-FFNP uptake was observed with the SSM3 tumors (average T:M, 9.0 and 8.8, respectively) (Fig. 2). SSM2 tumors showed ${ }^{18} \mathrm{~F}-\mathrm{FES}$ and ${ }^{18} \mathrm{~F}-$ FFNP uptake similar to that in the primary tumors (average T:M, 4.3 and 3.9, respectively). Although SSM1 tumors displayed mild ${ }^{18}$ F-FES uptake (T:M, $1.8 ; P<0.001$ ), they did not demonstrate statistically significant higher ${ }^{18} \mathrm{~F}-\mathrm{FFNP}$ uptake over muscle (T:M, $1.4 ; P=0.08$ ), consistent with previous results demonstrating SSM1 as ER $\alpha$-poor and PRnegative (17). Although the SSM3 tumors displayed greater ${ }^{18} \mathrm{~F}$-FES and ${ }^{18} \mathrm{~F}$-FFNP uptake than the SSM2 tumors, ${ }^{18} \mathrm{~F}$ FDG uptake was less in the SSM3 tumors (average T:M, 4.0) than in the SSM1 and SSM2 tumors (Supplemental Fig. 2). Because the SSM3 tumors displayed the greatest ${ }^{18} \mathrm{~F}-\mathrm{FES}$ and ${ }^{18}$ F-FFNP uptake, this cell line was utilized for subsequent experiments using hormonal therapies. 


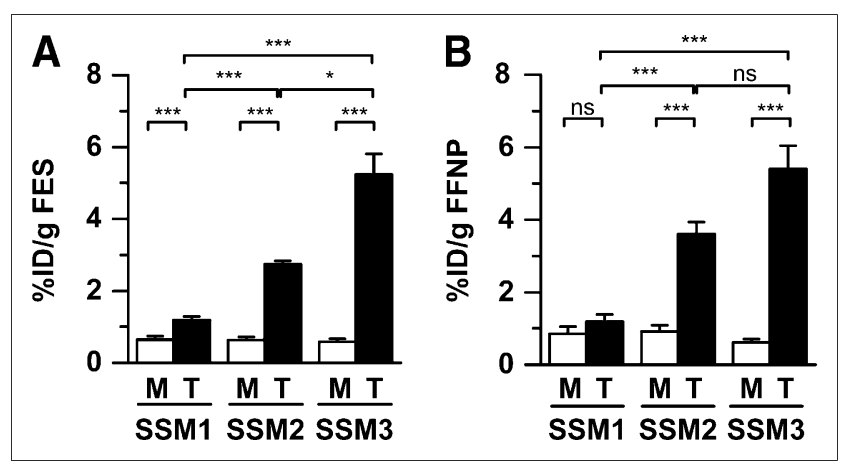

FIGURE 2. Female WT mice with SSM1 $(n=6), \operatorname{SSM} 2(n=4)$, or SSM3 $(n=6)$ tumors in right thoracic mammary fat pad were imaged using small-animal PET/CT with ${ }^{18} \mathrm{~F}-\mathrm{FES}(\mathrm{A})$ and ${ }^{18} \mathrm{~F}-\mathrm{FFNP}(\mathrm{B})$. Activity was measured in tumor and muscle. ns = not statistically significant. ${ }^{\star} P<0.05$. ${ }^{\star \star \star} P<0.001$.

\section{Estrogen-Inducible ${ }^{18}$ F-FFNP Uptake of SSM3 Tumors}

To use this preclinical model to test the ability of steroid hormone receptor imaging for predicting early response to hormonal therapy, we must confirm that $P G R$ behaves as an estrogen-regulated target gene in the SSM tumors. As an alternative approach to ovariectomy, SSM3-tumor-bearing WT mice were treated with letrozole, an aromatase inhibitor, in an attempt to decrease baseline PR protein expression such that maximum induction by estradiol could be detected, since aromatase inhibitor treatment of mice with intact ovaries has been shown to decrease serum estradiol levels (26). Baseline ${ }^{18} \mathrm{~F}$-FFNP small-animal PET was performed on mice treated for $2 \mathrm{~d}$ with letrozole, and the images were compared with those of untreated mice. No significant difference in ${ }^{18} \mathrm{~F}$-FFNP uptake was observed between the groups (Supplemental Fig. 3), indicating that baseline ${ }^{18}$ F-FFNP uptake cannot be lowered any further without ovariectomy. After baseline imaging, letrozole-treated mice were treated with estradiol for $24 \mathrm{~h}$ and reimaged with ${ }^{18} \mathrm{~F}-\mathrm{FFNP}$. The average T:M ratios increased from 3.6 for the untreated mice to 6.9 for the estrogen-stimulated mice (Fig. 3). A biodistribution assay performed after the posttreatment imaging session yielded similar results, with $3.8 \pm$ 0.3 percentage injected dose/g (T:M, 3.7) ${ }^{18} \mathrm{~F}$-FFNP uptake measured in the untreated tumors and $6.4 \pm 0.2$ percentage injected dose/g (T:M, 5.4) in the treated tumors $(P=$ 0.0003). Consistent with the agonist properties of estradiol, average uterine weights increased in the estrogen-stimulated mice $(120 \pm 5.7 \mathrm{mg})$, compared with untreated mice $(71.8 \pm$ $6.9 \mathrm{mg} ; P=0.0017)$. Thus, PR expression, reflected by ${ }^{18} \mathrm{~F}-$ FFNP uptake, is estrogen-inducible and indicative of functional $\mathrm{ER} \alpha$ signaling in the SSM3 tumors.

\section{Effect of the Pure ER Antagonist, Fulvestrant, on SSM3 Tumor Growth and ${ }^{18}$ F-FFNP, ${ }^{18}$ F-FES, and ${ }^{18}$ F-FDG Uptake}

Fulvestrant is a pure antiestrogen with several mechanisms of antagonistic action, including competitive inhibition of receptor binding with estradiol; interference with nucleocytoplasmic receptor shuttling, dimerization, and DNA binding; and targeting of ER for proteasomemediated degradation (27). SSM3-tumor-bearing WT mice were treated with vehicle control or fulvestrant for $2 \mathrm{wk}$ and then imaged with ${ }^{18} \mathrm{~F}-\mathrm{FFNP}$ at endpoint to test whether pharmacologic inhibition of estrogen signaling would decrease estrogen-regulated target genes such as PGR. Fulvestrant-treated mice showed significantly reduced tumoral ${ }^{18}$ F-FFNP uptake, compared with control mice (T:M, 3.6 and 4.9, respectively) (Fig. 4A), with a decrease in both PRA and PR-B protein levels (Supplemental Fig. 4). Consistent with these results, PR concentrations decreased from $1,670( \pm 480) \mathrm{fmol} / \mathrm{mg}$ of protein in the control tumors to $877( \pm 180) \mathrm{fmol} / \mathrm{mg}$ of protein in the fulvestrant-treated tumors as determined by a conventional in vitro PR ligand binding assay. Similarly, tumoral ${ }^{18} \mathrm{~F}$-FES uptake was also significantly decreased (T:M, 3.6 for fulvestrant-treated mice and 8.4 for control mice; Fig. 4B), reflective of the ability of fulvestrant to block receptor-radiotracer binding and to induce ER degradation. On semiquantitative Western blot analysis, ER $\alpha$ protein levels decreased from $543( \pm 38)$ to 277 ( \pm 52$) \mathrm{fmol} / \mathrm{mg}$ of protein in control and fulvestranttreated tumors, respectively $(P=0.008)$ (Supplemental Fig. 4). Similar results were obtained using a conventional in vitro ER ligand binding assay, which demonstrated $467( \pm 100) \mathrm{fmol} / \mathrm{mg}$ of protein in control tumors and $214( \pm 40) \mathrm{fmol} / \mathrm{mg}$ of protein in fulvestrant-treated tumors. Decreased ${ }^{18}$ F-FDG uptake was also observed in the fulvestrant-treated mice (T:M, 7.0 vs. 5.1) (Supplemental Fig. 5). Consistent with inhibition of estrogen signaling, growth of the fulvestrant-treated tumors was arrested, whereas tumors in the vehicle control group continued to progress $(P=0.03)$ (Fig. 4C). Further confirmation of the antagonistic function of fulvestrant was the observation that average uterine weights decreased in the fulvestrant-treated mice $(48.2 \pm 2.3 \mathrm{mg})$, compared with control mice

FIGURE 3. Female WT mice with SSM3 tumors in right thoracic mammary fat pad were treated with $50 \mu \mathrm{g}$ of intraperitoneal letrozole daily for $2 \mathrm{~d}(n=4)$ or were left untreated $(n=4)$. After baseline imaging, mice pretreated with letrozole were subsequently administered $20 \mu \mathrm{g}$ of subcutaneous estradiol. ${ }^{18} \mathrm{~F}-\mathrm{FFNP}$ small-animal PET of untreated mice $(-)$ and mice treated with letrozole followed by estradiol (Let-E2) was performed $24 \mathrm{~h}$ later. Activity was measured in tumor and muscle. Coronal fused 3-dimensional PET/CT images and quantification are shown. ${ }^{\star \star} P<0.01$.

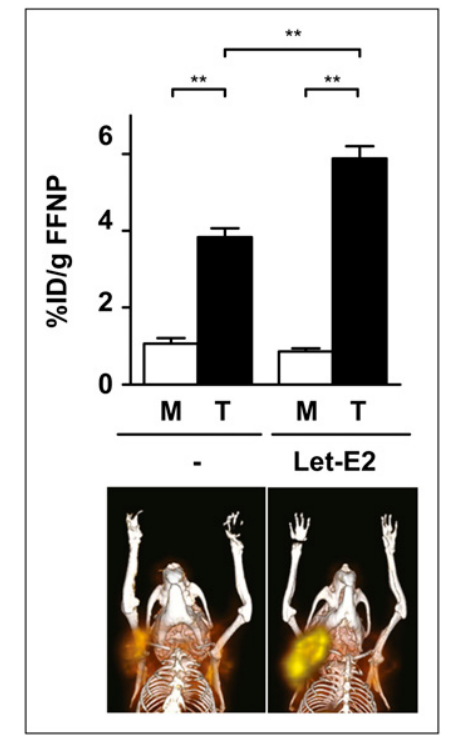




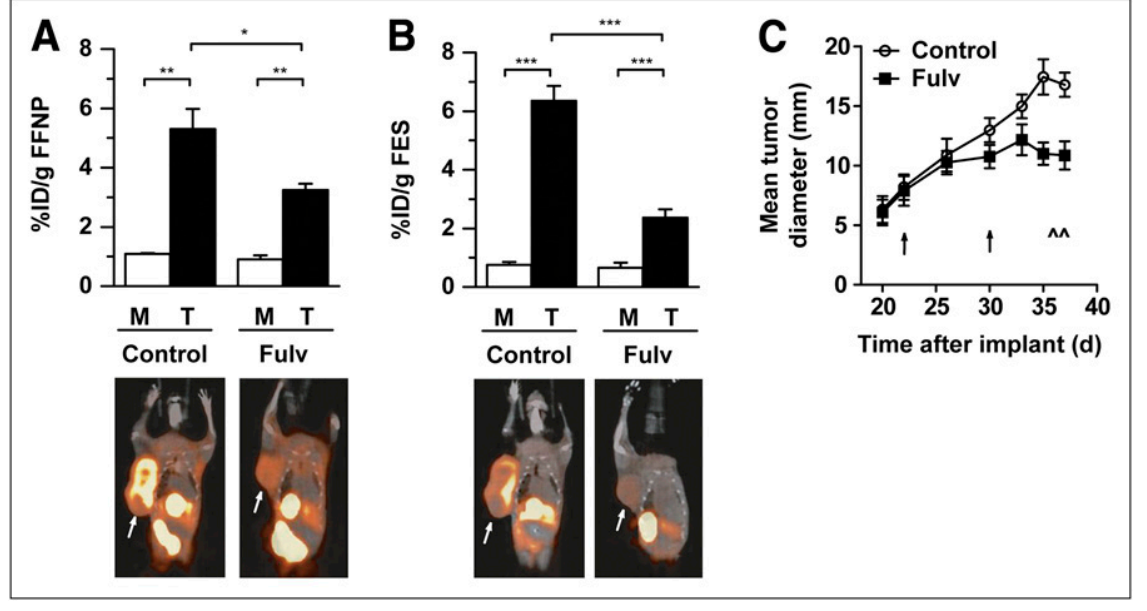

FIGURE 4. Female WT mice with SSM3 tumors in right thoracic mammary fat pad were treated with vehicle control $(n=5)$ or fulvestrant (Fulv; $n=5$ ) on days 23 and 30 after implantation. (A and B) Small-animal $\mathrm{PET} / \mathrm{CT}$ was performed using ${ }^{18} \mathrm{~F}-\mathrm{FFNP}(\mathrm{A})$ and ${ }^{18} \mathrm{~F}-\mathrm{FES}$ (B) on days 36 and 37 after implantation. Activity was measured in tumor (arrows) and muscle. (C) Tumor growth curve analysis (5 per group). Timing of treatments and imaging sessions is indicated by $\uparrow$ and ${ }^{\wedge}$, respectively. ${ }^{\star} P<0.05 .{ }^{* \star} P<0.01$. ${ }^{\star \star \star} P<0.001$.
(71.1 $\pm 5.5 \mathrm{mg} ; P=0.0048)$. Thus, ${ }^{18} \mathrm{~F}$-FFNP imaging is a useful in vivo biomarker of $\mathrm{ER} \alpha$ activity.

\section{Effect of the Pure ER Antagonist, Fulvestrant, on SSM2 Tumor Growth and ${ }^{18}$ F-FFNP, ${ }^{18}$ F-FES, and 18F-FDG Uptake}

We further examined the use of ${ }^{18} \mathrm{~F}$-FFNP imaging to reflect the inhibitory effects of fulvestrant on estrogen signaling using another $\mathrm{ER} \alpha^{+} / \mathrm{PR}^{+}$tumor cell line, SSM2. WT mice bearing SSM2 tumors were treated with vehicle control or fulvestrant for $10 \mathrm{~d}$ and then imaged with ${ }^{18} \mathrm{~F}-$ FFNP, ${ }^{18}$ F-FES, and ${ }^{18}$ F-FDG PET at the conclusion of the treatment. Surprisingly, ${ }^{18} \mathrm{~F}$-FFNP uptake was unchanged in the fulvestrant-treated group even though ${ }^{18} \mathrm{~F}$-FES uptake decreased (Figs. 5A and 5B). Western blot analysis confirmed the imaging finding, because PR protein levels were stable with fulvestrant treatment whereas ER $\alpha$ levels were reduced (Supplemental Fig. 6). Using semiquantitative Western blot analysis, ER $\alpha$ protein levels decreased from $300( \pm 25)$ to $175( \pm 25) \mathrm{fmol} / \mathrm{mg}$ of protein in control and fulvestrant-treated SSM2 tumors, respectively $(P=0.047)$. Therefore, whereas fulvestrant lacks the ability to inhibit PR expression and ${ }^{18} \mathrm{~F}-\mathrm{FFNP}$ uptake in the SSM2 tumors, the compound is biologically active in its ability to mediate ER $\alpha$ protein downregulation (Supplemental Fig. 6) and decrease uterine weight $(43.1 \pm 3.5 \mathrm{mg}$ in the fulvestrant-treated mice, compared with $73.2 \pm 11 \mathrm{mg}$ in the control mice; $P=0.0071$ ). ${ }^{18} \mathrm{~F}-\mathrm{FDG}$ uptake was not affected (Supplemental
Fig. 7), consistent with the inability of fulvestrant to attenuate the tumor growth of the drug-treated cohort (Fig. 5C). On the basis of the results demonstrated in Figures 4 and $5,{ }^{18} \mathrm{~F}-\mathrm{FFNP}$ imaging but not ${ }^{18} \mathrm{~F}$-FES imaging can discriminate between $\mathrm{ER} \alpha^{+} / \mathrm{PR}^{+}$tumors with differing growth responses to antiestrogen therapy (i.e., SSM3 being the "responders" and SSM2 the "nonresponders").

\section{Early Effect of Fulvestrant on ${ }^{18} \mathrm{~F}$-FFNP Uptake of SSM3 Tumors Before Tumor Growth Inhibition}

An important goal of PET in cancer research is to noninvasively predict early responses to therapies before overt changes in tumor size in order to guide further management. After establishing that 2 wk of fulvestrant treatment decreases ${ }^{18}$ F-FFNP uptake of SSM3 tumors (reflecting blockade of the estrogen signaling pathway) and inhibits further tumor growth, we tested whether changes in ${ }^{18} \mathrm{~F}$-FFNP uptake can be detected early after the initiation of antiestrogen treatment ( $3 \mathrm{~d}$ ), before changes in tumor growth occur.

Pretreatment small-animal PET with ${ }^{18} \mathrm{~F}-\mathrm{FFNP}$ and ${ }^{18} \mathrm{~F}-$ FES showed no significant difference $(P=0.76$ and 0.82 , respectively) in radiotracer uptake between the SSM3-tumor-bearing mice randomized to receive fulvestrant versus the control mice. Three and $4 \mathrm{~d}$ after treatment with a single dose of fulvestrant, imaging was repeated and showed decreased ${ }^{18} \mathrm{~F}$-FFNP and ${ }^{18} \mathrm{~F}$-FES uptake in the fulvestranttreated mice, compared with controls (T:M, 7.4-5.4 for ${ }^{18} \mathrm{~F}$ -
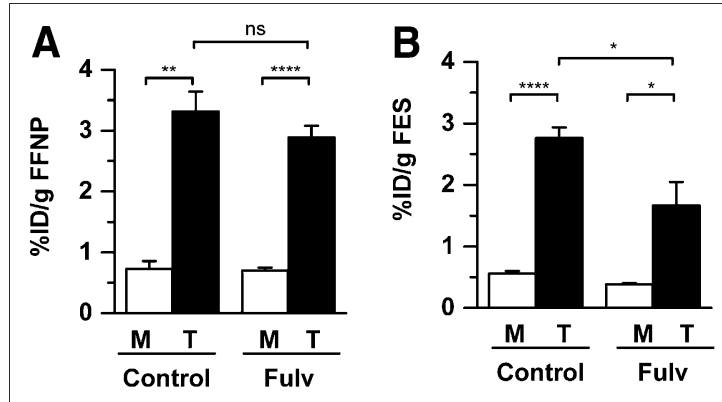

FIGURE 5. (A and B) Female WT mice with SSM2 tumors in right thoracic mammary fat pad were treated with vehicle control $(n=4)$ or fulvestrant (Fulv; $n=4$ ) on day 47 after implantation and imaged with ${ }^{18} \mathrm{~F}-\mathrm{FFNP}$ (A) and ${ }^{18} \mathrm{~F}-\mathrm{FES}$ (B) on days 56 and 57 after implantation, respectively. Activity was measured in tumor and muscle. (C) Tumor growth curve analysis (4 per group). Timing of treatment and imaging sessions is indicated by $\uparrow$ and $\boldsymbol{\wedge}$, respectively. ns $=$ not statistically significant. ${ }^{\star} P<0.05 .{ }^{\star *} P<$ 0.01. ${ }^{\star \star \star \star} P<0.0001$. 
FFNP and 6.4-3.9 for ${ }^{18}$ F-FES) (Figs. 6A and 6B). Mean tumor diameter remained unchanged during the timing of the pre- and posttreatment imaging sessions (days 22 and 26 after implantation) (Fig. 6C). The experiment was continued until a separation in the tumor growth curves was confirmed. On day 29 after implantation, ${ }^{18}$ F-FDG imaging showed decreased ${ }^{18} \mathrm{~F}-\mathrm{FDG}$ uptake in the fulvestrant-treated mice, compared with controls (T:M, 3.8-2.8), confirming the antitumor effect of fulvestrant on SSM3 tumors (Supplemental Fig. 8). Thus, ${ }^{18} \mathrm{~F}$-FFNP is a useful in vivo biomarker of the estrogen signaling pathway and can indicate early response to endocrine therapy.

\section{DISCUSSION}

Using a preclinical model of breast cancer, we have demonstrated how imaging steroid hormone receptors can be used to predict response to endocrine therapy. Spontaneous mammary carcinomas that develop in aged female STAT $^{-1-}$ mice were shown with small-animal PET to express ER $\alpha$ and PR in vivo, and this finding was confirmed with in vitro receptor analysis. Classic estrogen-induced ER target gene regulation was demonstrated by increased ${ }^{18} \mathrm{~F}$ FFNP uptake using implanted SSM3 tumors, validating the hormone responsiveness of these tumors. We identified an imaging profile (decreased ${ }^{18} \mathrm{~F}-\mathrm{FES}$, decreased ${ }^{18} \mathrm{~F}-\mathrm{FFNP}$, and decreased ${ }^{18} \mathrm{~F}$-FDG uptake) that distinguished $\mathrm{ER} \alpha^{+} /$ $\mathrm{PR}^{+}$SSM3 tumors that are sensitive to growth inhibition by the pure ER antagonist, fulvestrant, from $\mathrm{ER} \alpha^{+} / \mathrm{PR}^{+} \mathrm{SSM} 2$ tumors that are resistant (decreased ${ }^{18} \mathrm{~F}-\mathrm{FES}$, stable ${ }^{18} \mathrm{~F}$ FFNP, and stable ${ }^{18}$ F-FDG uptake). Most importantly, the imaging changes occurred before measurable changes in tumor size, suggesting that early alternative intervention may be possible for nonresponsive tumors. The mechanism responsible for divergent responses of SSM2 and SSM3 tumors to fulvestrant is currently not known and may relate to alternative growth signaling pathways upregulated in hormone-resistant breast cancers (1). However, the fact that PET with ${ }^{18} \mathrm{~F}$-FES and ${ }^{18} \mathrm{~F}$-FFNP can distinguish $\mathrm{ER} \alpha^{+} /$ $\mathrm{PR}^{+}$mouse mammary tumors that respond favorably to endocrine therapies (SSM3) from those that do not (SSM2) suggests that a similar approach might prove useful in dis- tinguishing between $\mathrm{ER} \alpha^{+} / \mathrm{PR}^{+}$human breast cancers that are responsive or nonresponsive to endocrine therapies and thus facilitate the selection of therapies most appropriate for individual patients. The combination of noninvasive imaging with gene expression screening assays, such as Oncotype Dx (Genomic Health, Inc.), which is used to predict chemotherapy benefit for patients with early-stage breast cancer, could further advance personalized medicine.

Small-animal imaging using ${ }^{18}$ F-FES as a marker of ER $\alpha$ expression in breast cancer has been reported. Aliaga et al. used MC7-L1 and MC4-L2 cells, which are $\mathrm{ER} \alpha^{+} / \mathrm{PR}^{+}$ mammary ductal carcinoma cell lines derived from medroxyprogesterone acetate-induced adenocarcinomas in female BALB/c mice, with ER levels of $217 \pm 33 \mathrm{fmol} /$ $\mu \mathrm{g}$ DNA in MC7-L1 tumors and $530 \pm 132 \mathrm{fmol} / \mu \mathrm{g}$ DNA in MC4-L2 tumors (28). Tumor-to-reference tissue ratios of ${ }^{18} \mathrm{~F}$-FES uptake, as measured by PET at $1 \mathrm{~h}$ after injection, were 4.4 and 6.7 , respectively, in tumors grown from the 2 cell lines (28). For comparison, biodistribution studies of 7,12-dimethylbenz(a)anthracene-induced mammary tumors in Sprague-Dawley rats yielded a tumor-to-nontarget tissue ratio of approximately $10(8)$, whereas ${ }^{18} \mathrm{~F}$-FES uptake of MCF-7 xenograft tumors (a well-characterized $\mathrm{ER} \alpha^{+} / \mathrm{PR}^{+}$ human breast cancer cell line) grown in severe combined immunodeficiency mice yielded a T:M ratio of 5.7 (29). These values are of similar magnitude to the T:M ratios of the primary STAT $1^{-1-}$ mammary tumors and the transplanted SSM2 and SSM3 tumors reported here (4.5, 4.3, and 9.0, respectively). Therefore, the ${ }^{18} \mathrm{~F}$-FES uptake seen in our preclinical model system is in concordance with that of other published models.

A complication of using ${ }^{18} \mathrm{~F}-\mathrm{FES}$ to monitor ER expression during endocrine therapy is that compounds that directly bind ER (e.g., fulvestrant, tamoxifen, and raloxifene) interfere with binding of the radiopharmaceutical to the receptor (30). This was reported by McGuire et al., who observed a decrease in ${ }^{18} \mathrm{~F}$-FES uptake in all 16 patients with metastatic breast cancer after initiation of tamoxifen or toremifene therapy (31). Furthermore, agents that affect ER protein levels will also influence ${ }^{18} \mathrm{~F}-\mathrm{FES}$ binding. Thus, decreased ${ }^{18} \mathrm{~F}$-FES uptake of tumors treated with fulvestrant
FIGURE 6. Female WT mice with implanted SSM3 tumors were imaged with ${ }^{18} \mathrm{~F}-\mathrm{FES}$ and ${ }^{18} \mathrm{~F}-\mathrm{FFNP}$ on postimplantation day 21 and were treated with vehicle control or fulvestrant (Fulv; 6 per group) after baseline ${ }^{18} \mathrm{~F}-\mathrm{FFNP}$ imaging. ( $\mathrm{A}$ and $\mathrm{B}$ ) Posttreatment ${ }^{18}$ F-FFNP $(A)$ and ${ }^{18}$ F-FES $(B)$ imaging was performed on days 25 and 26, respectively. Activity was measured in tumor and muscle. (C) Tumor growth curve analysis (6 per group). Timing of imaging sessions was as follows: postimplantation day $21=$ pretreatment ${ }^{18} \mathrm{~F}-\mathrm{FES}$ and pretreatment ${ }^{18} \mathrm{~F}-$ FFNP, day 25 = posttreatment ${ }^{18} \mathrm{~F}-\mathrm{FFNP}$, and day 26 = posttreatment ${ }^{18} \mathrm{~F}-\mathrm{FES}$. Timing of treatment and imaging sessions is indicated by $\uparrow$ and ${ }^{\wedge}$, respectively. ${ }^{\star \star} P<0.01$. ${ }^{\star \star \star} P<0.001$. ${ }^{\star \star \star \star} P<0.0001$.
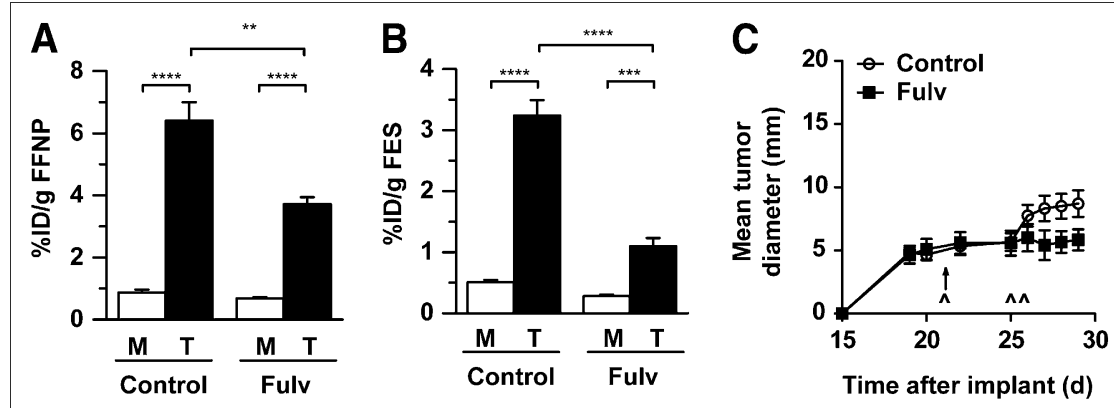
reflects both blockade of radiopharmaceutical binding to ER and decreased ER protein levels due to receptor degradation. In this study, ${ }^{18} \mathrm{~F}$-FES uptake was useful in identifying the $\mathrm{ER}^{+}$tumors but was not sufficient to predict response to endocrine therapy because ${ }^{18} \mathrm{~F}$-FES uptake decreased in both the fulvestrant-sensitive and the fulvestrantresistant tumors. Similarly in human studies, posttreatment ${ }^{18} \mathrm{~F}$-FES uptake decreased in breast cancer patients with and without response to tamoxifen $(12,32)$. However, a greater reduction in standardized uptake values $7-10 \mathrm{~d}$ after initiation of tamoxifen therapy was seen in responders than in nonresponders $(55 \% \pm 14 \%$ decrease vs. $19 \% \pm$ $17 \%, P=0.0003)(12)$. Our data followed a similar trend $\left(60 \% \pm 9 \%\right.$ decrease in ${ }^{18} \mathrm{~F}$-FES uptake for SSM3 tumors, compared with $42 \% \pm 10 \%$ decrease for SSM2) but are not statistically significant $(P=0.2)$. Therefore, a reduction in ${ }^{18} \mathrm{~F}-\mathrm{FES}$ uptake alone cannot reliably distinguish nonresponders from responders.

Because $P G R$ is a classic estrogen-regulated target gene, ${ }^{18}$ F-FFNP PET allows for assessment of functional ER $\alpha$ signaling during endocrine therapy and avoids the problem of the therapeutic agent interfering with the imaging compound, as experienced with ${ }^{18} \mathrm{~F}$-FES. To the best of our knowledge, there are no published reports of ${ }^{18} \mathrm{~F}-\mathrm{FFNP}$ uptake by mammary tumors in rodents with which we can compare our results. ${ }^{18}$ F-FFNP imaging of patients with newly diagnosed primary breast cancer before treatment showed a tumor-to-normal breast tissue ratio of $2.6 \pm$ 0.9 for $\mathrm{PR}^{+}$cancers (15), which is slightly lower than the ${ }^{18} \mathrm{~F}-\mathrm{FFNP}$ uptake of primary STAT $1^{-1-}$ tumors and implanted SSM2 and SSM3 cell lines. In our study, early changes in ${ }^{18} \mathrm{~F}$-FFNP uptake by $\mathrm{ER} \alpha^{+}$tumors predicted response to fulvestrant treatment. It is notable, however, that a baseline "positive" ${ }^{18}$ F-FFNP result alone was insufficient to distinguish nonresponders from responders. A similar observation for breast cancer patients was made by the Early Breast Cancer Trialists' Collaborative Group, which found that pretreatment PR status determined by ligand binding assay did not yield any additional predictive power for response to tamoxifen over ER $\alpha$ status alone (33). Similar to that study, Howell et al. showed no significant difference in survival or time to progression when analyzing PR status using only the pretreatment biopsy in patients with $\mathrm{ER} \alpha^{+}$tumors. However, an increase in PR seen on repeated biopsy within a few weeks after initiating tamoxifen therapy did correlate with prolonged time to progression and improved survival (34). Thus, it appears that pretreatment measurement of ER $\alpha$ together with pretreatment and early posttreatment assessment of PR expression after the initiation of endocrine therapy yields the best predictive information.

\section{CONCLUSION}

De novo and acquired resistance to endocrine therapy remains a major obstacle to optimal management. Thus, there is a need to identify which $\mathrm{ER} \alpha^{+} / \mathrm{PR}^{+}$tumors are most likely to respond to endocrine therapy so that ineffective therapies can be efficiently bypassed. This work suggests that measuring baseline ER $\alpha$ levels by ${ }^{18} \mathrm{~F}$-FES PET and early changes in PR by ${ }^{18} \mathrm{~F}$-FFNP PET is a potentially useful strategy to identify responders and nonresponders to endocrine therapy. Further studies are planned to longitudinally monitor tumor progression to endocrine resistance and to investigate new therapies.

\section{DISCLOSURE STATEMENT}

The costs of publication of this article were defrayed in part by the payment of page charges. Therefore, and solely to indicate this fact, this article is hereby marked "advertisement" in accordance with 18 USC section 1734.

\section{ACKNOWLEDGMENTS}

We thank Margaret Morris, Amanda Roth, Ann Stroncek, and Lori Strong for their excellent technical assistance (Small Animal Imaging Facility, Washington University School of Medicine). This work was supported by grants U01CA141541-01 and R01CA025836 from the National Cancer Institute. No other potential conflict of interest relevant to this article was reported.

\section{REFERENCES}

1. Osborne CK, Schiff R. Mechanisms of endocrine resistance in breast cancer. Annu Rev Med. 2011;62:233-247.

2. Hammond ME, Hayes DF, Dowsett M, et al. American Society of Clinical Oncology/College of American Pathologists guideline recommendations for immunohistochemical testing of estrogen and progesterone receptors in breast cancer (unabridged version). Arch Pathol Lab Med. 2010;134:e48-e72.

3. Kuukasjärvi T, Kononen J, Helin H, Holli K, Isola J. Loss of estrogen receptor in recurrent breast cancer is associated with poor response to endocrine therapy. J Clin Oncol. 1996;14:2584-2589.

4. Liedtke C, Broglio K, Moulder S, et al. Prognostic impact of discordance between triple-receptor measurements in primary and recurrent breast cancer. Ann Oncol. 2009;20:1953-1958.

5. Katzenellenbogen JA, Welch MJ, Dehdashti F. The development of estrogen and progestin radiopharmaceuticals for imaging breast cancer. Anticancer Res. 1997; 17:1573-1576.

6. Yoo J, Dence CS, Sharp TL, Katzenellenbogen JA, Welch MJ. Synthesis of an estrogen receptor beta-selective radioligand: 5-[18 $\mathrm{F}]$ fluoro-(2R,3S)-2,3-bis(4-hydroxyphenyl)pentanenitrile and comparison of in vivo distribution with 16alpha$\left[{ }^{18}\right.$ F]fluoro-17beta-estradiol. J Med Chem. 2005;48:6366-6378.

7. Kiesewetter DO, Kilbourn MR, Landvatter SW, Heiman DF, Katzenellenbogen JA, Welch MJ. Preparation of four fluorine-18-labeled estrogens and their selective uptakes in target tissues of immature rats. J Nucl Med. 1984;25:1212-1221.

8. Mathias CJ, Welch MJ, Katzenellenbogen JA, et al. Characterization of the uptake of 16 alpha-([ $\left.{ }^{18} \mathrm{~F}\right]$ fluoro $)-17$ beta-estradiol in DMBA-induced mammary tumors. Int J Rad Appl Instrum B. 1987;14:15-25.

9. Mintun MA, Welch MJ, Siegel BA, et al. Breast cancer: PET imaging of estrogen receptors. Radiology. 1988;169:45-48.

10. Peterson LM, Mankoff DA, Lawton T, et al. Quantitative imaging of estrogen receptor expression in breast cancer with PET and ${ }^{18} \mathrm{~F}$-fluoroestradiol. $\mathrm{J}$ Nucl Med. 2008;49:367-374.

11. Dehdashti F, Mortimer JE, Siegel BA, et al. Positron tomographic assessment of estrogen receptors in breast cancer: comparison with FDG-PET and in vitro receptor assays. J Nucl Med. 1995;36:1766-1774.

12. Mortimer JE, Dehdashti F, Siegel BA, Trinkaus K, Katzenellenbogen JA, Welch MJ. Metabolic flare: indicator of hormone responsiveness in advanced breast cancer. J Clin Oncol. 2001;19:2797-2803. 
13. Linden HM, Stekhova SA, Link JM, et al. Quantitative fluoroestradiol positron emission tomography imaging predicts response to endocrine treatment in breast cancer. J Clin Oncol. 2006;24:2793-2799.

14. Buckman BO, Bonasera TA, Kirschbaum KS, Welch MJ, Katzenellenbogen JA. Fluorine-18-labeled progestin 16 alpha, 17 alpha-dioxolanes: development of high-affinity ligands for the progesterone receptor with high in vivo target site selectivity. J Med Chem. 1995;38:328-337.

15. Dehdashti F, Laforest R, Gao F, et al. Assessment of progesterone receptors in breast carcinoma by PET with $21-{ }^{18} \mathrm{~F}$-fluoro-16alpha,17alpha-[(R)-(1'-alphafurylmethylidene)dioxy]-19-norpregn-4-ene-3,20-dione. J Nucl Med. 2012;53: 363-370.

16. Meraz MA, White JM, Sheehan KC, et al. Targeted disruption of the Stat 1 gene in mice reveals unexpected physiologic specificity in the JAK-STAT signaling pathway. Cell. 1996;84:431-442.

17. Chan SR, Vermi W, Luo J, et al. STAT1-deficient mice spontaneously develop estrogen receptor alpha-positive luminal mammary carcinomas. Breast Cancer Res. January 20, 2012 [Epub ahead of print].

18. Vijaykumar D, Mao W, Kirschbaum KS, Katzenellenbogen JA. An efficient route for the preparation of a 21-fluoro progestin-16 alpha, 17 alpha-dioxolane, a highaffinity ligand for PET imaging of the progesterone receptor. J Org Chem. 2002;67:4904-4910.

19. Zhou D, Dence CS, Katzenellenbogen JA, Welch MJ. Synthesis of [F-18]fluoro furanyl norprogesterone (FFNP) for clinical evaluation as a PET imaging agent for progesterone receptor (PR) in breast tumors [abstract]. J Labelled Comp Radiopharm. 2011;54(suppl):S497.

20. Lim JL, Zheng L, Berridge MS, Tewson TJ. The use of 3-methoxymethyl-16 beta, 17 beta-epiestriol-O-cyclic sulfone as the precursor in the synthesis of F-18 16 alpha-fluoroestradiol. Nucl Med Biol. 1996;23:911-915.

21. Dence C, Fowler A, Zhou D, et al. 16 alpha- $\left[{ }^{18}\right.$ F $]$ fluoro-17 beta-estradiol (FES) metabolite analyses in rodent tissue micro samples by solid-phase (SP) Florisil columns [abstract]. J Nucl Med. 2011;52 (suppl 1):298P.

22. Qi J, Leahy RM, Cherry SR, Chatziioannou A, Farquhar TH. High-resolution 3D Bayesian image reconstruction using the microPET small-animal scanner. Phys Med Biol. 1998;43:1001-1013.
23. Saji S, Sakaguchi H, Andersson S, Warner M, Gustafsson J. Quantitative analysis of estrogen receptor proteins in rat mammary gland. Endocrinology. 2001;142: 3177-3186.

24. Katzenellenbogen JA, Heiman DF, Carlson KE, Lloyd JE. In vitro and in vivo steroid receptor assays in the design of estrogen radiopharmaceuticals. In: Eckelman W, ed. Receptor Binding Radiotracers. Vol 1. Boca Raton, FL: CRC Press; 1982:93-126.

25. Sullivan WP, Smith DF, Beito TG, Krco CJ, Toft DO. Hormone-dependent processing of the avian progesterone receptor. J Cell Biochem. 1988;36:103-119.

26. Fatum M, Gyo Y, Diana P, Laufer N, Simon A. Is estradiol mandatory for an adequate follicular and embryo development? A mouse model using aromatase inhibitor (anastrozole). J Assist Reprod Genet. 2006;23:407-412.

27. Howell A. Pure oestrogen antagonists for the treatment of advanced breast cancer. Endocr Relat Cancer. 2006;13:689-706.

28. Aliaga A, Rousseau JA, Ouellette R, et al. Breast cancer models to study the expression of estrogen receptors with small animal PET imaging. Nucl Med Biol. 2004;31:761-770.

29. Downer JB, Jones LA, Katzenellenbogen JA, Welch MJ. Effect of administration route on FES uptake into MCF-7 tumors. Nucl Med Biol. 2001;28:397-399.

30. Linden HM, Kurland BF, Peterson LM, et al. Fluoroestradiol positron emission tomography reveals differences in pharmacodynamics of aromatase inhibitors, tamoxifen, and fulvestrant in patients with metastatic breast cancer. Clin Cancer Res. 2011;17:4799-4805.

31. McGuire AH, Dehdashti F, Siegel BA, et al. Positron tomographic assessment of 16 alpha- $\left[{ }^{18} \mathrm{~F}\right]$ fluoro-17 beta-estradiol uptake in metastatic breast carcinoma. J Nucl Med. 1991;32:1526-1531.

32. Dehdashti F, Flanagan FL, Mortimer JE, Katzenellenbogen JA, Welch MJ, Siegel BA. Positron emission tomographic assessment of "metabolic flare" to predict response of metastatic breast cancer to antiestrogen therapy. Eur J Nucl Med. 1999;26:51-56.

33. Davies C, Godwin J, Gray R, et al. Relevance of breast cancer hormone receptors and other factors to the efficacy of adjuvant tamoxifen: patient-level meta-analysis of randomised trials. Lancet. 2011;378:771-784.

34. Howell A, Harland RN, Barnes DM, et al. Endocrine therapy for advanced carcinoma of the breast: relationship between the effect of tamoxifen upon concentrations of progesterone receptor and subsequent response to treatment. Cancer Res. 1987;47:300-304. 